\title{
Numerical Modeling of Air-Based Bus Seat
}

\author{
Chee Fai Tan ${ }^{1, a}$, K.F. Liew ${ }^{1}$, S.N. Khalil ${ }^{1}$, M.R. Said, W. Chen², \\ G.W.M. Rauterberg' ${ }^{2}$, J. Karjanto' ${ }^{1}$, Z.T. Yau', B.L. Tan ${ }^{3}$, and T.L. Lim ${ }^{3}$ \\ ${ }^{1}$ Integrated Design Research Group (IDeA), Centre of Advanced Research on Energy, Faculty of \\ Mechanical Engineering, Universiti Teknikal Malaysia Melaka, Durian Tunggal, Melaka, Malaysia \\ ${ }^{2}$ Designed Intelligence Group, Department of Industrial Design, Eindhoven University of \\ Technology, Eindhoven, the Netherlands \\ ${ }^{3} \mathrm{TKH}$ Manufacturing Private Limited, Selangor, Malaysia \\ acheefai@utem.edu.my
}

Keywords: Smart system, air-based, aircraft seat.

\begin{abstract}
Travel with long hours will create discomfort feeling for passenger especially express bus passenger. Long hour travel will create physiological stress on passenger. It may due to seat space limitation, noise, vibration, seat hardness as well as seat comfort. Seat comfort is a subjective feeling that related to psychological aspect of passenger. In this project, the bus passenger seat is integrated with air-based and gel-based material. In Malaysia, most of the express coaches are using polyurethane foam based cushion in the seat padding. This type of the seat padding may cause a bus passenger who sit for long journey will feel uncomfortable and fatigue. There are two main causes which lead to seating discomfort which is vibration and pressure distribution on the seat. The new design a bus passenger seat is using air-based cushion to improve the seating comfort. The air-based seat was validated by using MatLab SimuLINK software. In the model validation process, the parameters of air cell height gave effect on the pressure change rate of air cushion model. The comfortable level of the air cushion could be improved by reducing the pressure change rate and cell height.
\end{abstract}

\section{Introduction}

The term of "seat comfort" is mean that the short-term effect of feeling of a seat on a human body. This will be the sensation usually appear during sitting on a seat for a short interval of time. The feel of "Comfort" is a vague or ambiguous concept and generally defined as lack of discomfort [1-3]. In contrast, "driver fatigue" defines the physical impairments due to experience the seat dynamics for a long time. These uncomfortable condition are known in nature and include reducing in attention during driving, decision-making not correctly, reaction time slow down and vigilance [4]. For example, a tractor driver may exposure a lot of tension in physical and mental. The operator work performance will be very poor if the seat is not comfortable and there is also a possibility of accidents [5].

The consumer expectations for a comfortable automobile seat keep increasing and the development of comfortable vehicle seat still in progress. The automobile seat comfort is designed and came out with an ergonomics background which is developed in the field of applied science [6]. In the automotive seating industry, the seat development is focused on objective and measurable laboratory standards that can relate with the performance measures. The performance measures of seat comfort for automobile based on human physiology and biomechanics. The mechanisms of the seat comfort are including pressure distribution, thermal comfort, vibration transmissibility and other [6].

Firstly, some of the researchers recommend that the pressure distribution will affects the perceptions of seat comfort. Pressure distribution at human-seat interface is one of the important cause affecting the seating comfort and work efficiency of various worker [7]. The appearance of 
the high pressure at the human-seat interface affect the soft tissue deformation leading to restricted blood and nutrient flows in the part of the body and bring discomfort to the human [8]. So, a seat with a good pressure distribution brings a suitable and balanced support to body areas during the contact on the seat.

Secondly, the thermal comfort also one of the important performance measures for seat comfort. The thermal comfort is a combination of temperature and humidity of the skin surface than can bring to discomfort. Most of reason is because of the increasing in the coefficient of friction when the skin is moist [6]. There is a ready-made seats with different materials are studied by the physiological laboratory test methods skin model and seat comfort tester. In the climatic chamber shown the results that the fabric cover produces more sweat compare than leather which mean fabric cover bring more discomfort than leather seat [9].

Next, the vibration transmissibility in vertical direction is one of the most investigated objective measures of seat comfort. Human will experience the vibration to some degree in any transportation or moving vehicle which is car, truck, bus, train, airplane or boat. The frequency range of 2-6 Hz will bring the hazard to the human operator because the resonance occurs within this frequency range. Then, the design parameters improvement for tractor seats is needed to increase the reductions in the level of ride vibrations exposure by tractor operators [10].

\section{Methodology}

Numerical Modeling. In the numerical modelling, the MatLab SimuLINK software was used to simulate the air cushion model. There are main program and the sub-program to complete the model validation. The development of the program will discuss briefly in this sub-chapter.

Main Program. The main program in the MatLab SimuLINK is use to identify the initial and the final conditions of the air cell. The initial air cell pressure will be $40 \mathrm{mmHg}$ which about $5.33 \mathrm{KPa}$ and this value is referring from the Advanced Vehicle Dynamics Laboratory [11]. By comparing both conditions, the main program will calculate the pressure drop after the weight applied in the air cell 1. Due to the pressure change in the air cell 1, so the volume of air in the air cell 1 and air cell 2 will be different. The average velocity and volume flow rate will be determined in the end of the main program. Besides, the derivative SimuLINK block set after the pressure drop is used to determine the pressure change rate of the air cell as shown in the Fig. 1.

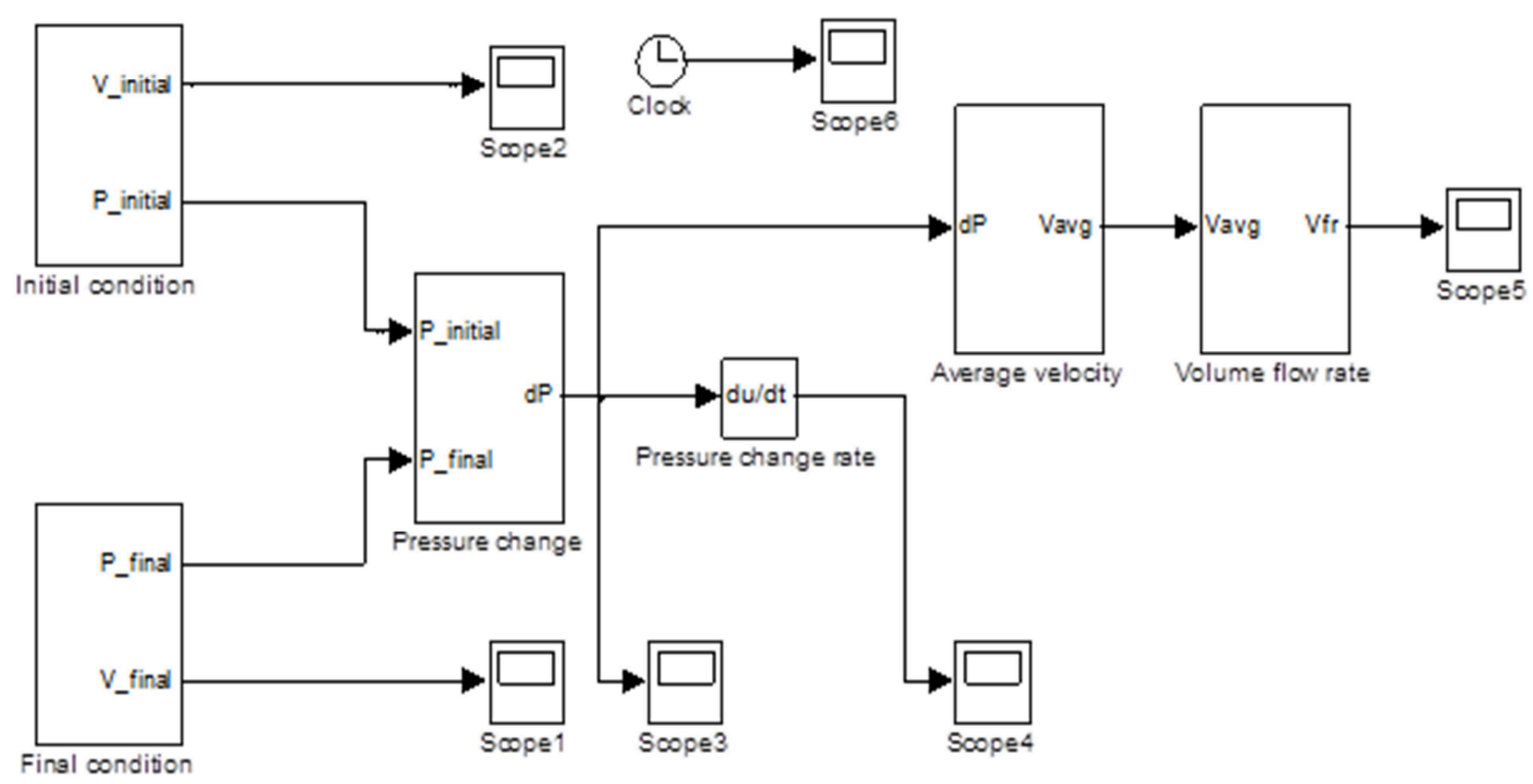

Fig.1.The main program in MatLab SimuLINK 
Sub-Program.The sub-program modeled in the MatLab SimuLINK is used to identify the initial and final conditions of the air cells. The initial condition is according to the assumption and set based on the reference. Next, the final condition will identify after the weight applied on the air cell and the weight is just about the $80 \%$ of seated person's weight in the assumption. After the weight applied on the air cushion model, the displacement will calculated based on the Hooke's law. The volume of the air cell will reduce in the final condition due to decrease in the air cell height. Based on the final volume of the air cell, the final pressure will be determined by using the Boyle's law as shown in the Fig. 2.

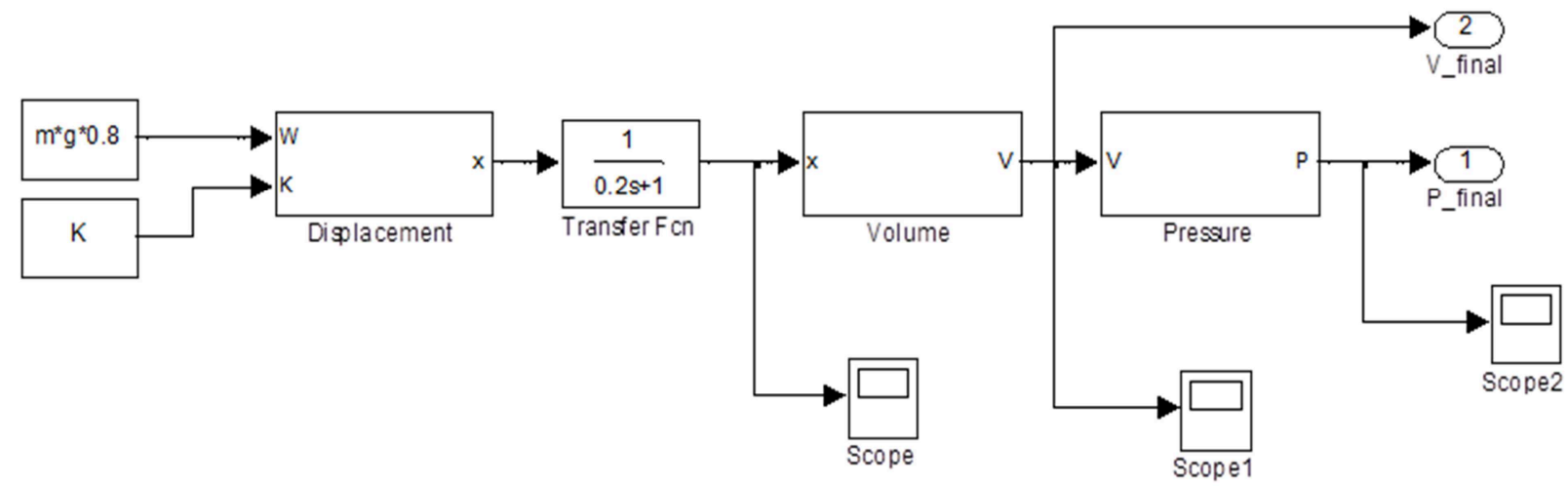

Fig.2: The sub-program to calculate the final conditions

Since, the initial and final conditions are calculated, the data will contribute to the main program to determine the pressure change rate and volume flow rate as shown in the sub-chapter previously.

\section{Result and Discussion}

Weight versus Air Cell Height. The air cell height is compare with the bus passenger weight. The passenger weight is defined as $60 \mathrm{~kg}, 80 \mathrm{~kg}$ and $100 \mathrm{~kg}$. During the modeling process, the increased of air cell height reduced the pressure change rate. Besides, the increasing bus passenger weightwas increased the pressure change rate. Based on these two conditions, the comparison graph is showed in the Fig. 3.

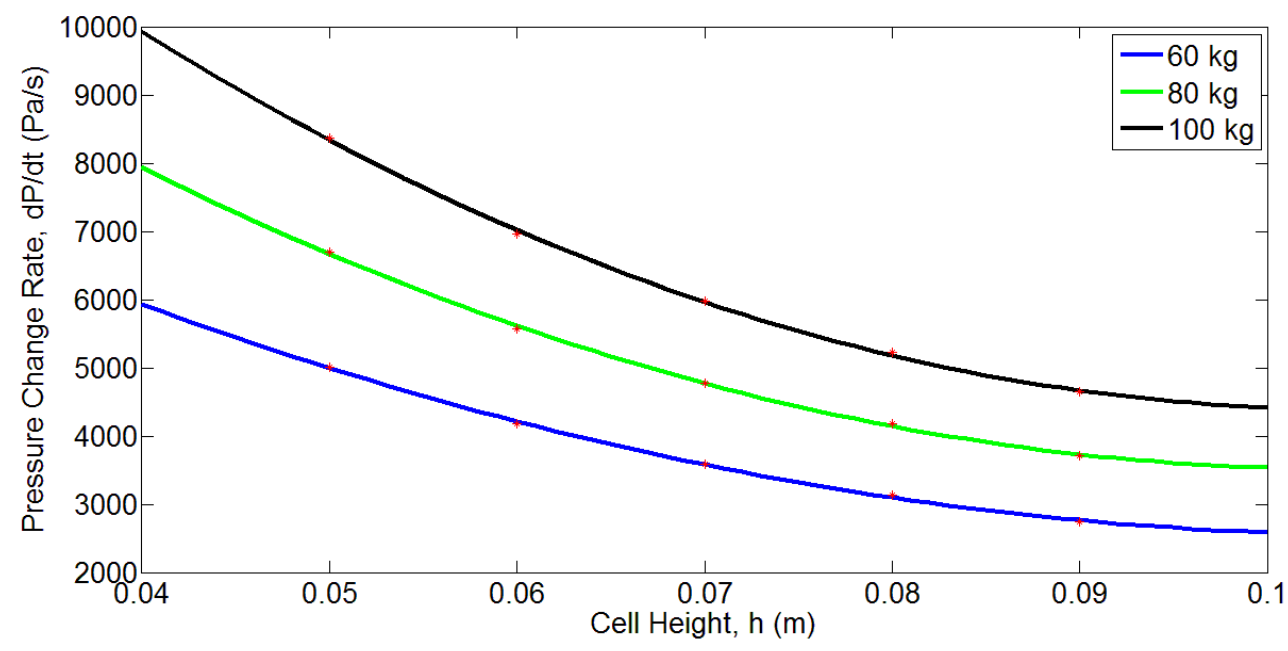

Fig.3:Comparison of different weight with increasing of air cell height

Table 3 showed the percentage of pressure change rate for each of different weight to show the different when the air cell height increasing. 
Table 3: Summary of percentage pressure change rate with different weights

\begin{tabular}{cc}
\hline Weight (kg) & $\begin{array}{c}\text { \% Decrease in } \\
\text { Pressure Change Rate }\end{array}$ \\
\hline 60 & $45 \%$ \\
80 & $44 \%$ \\
100 & $44 \%$ \\
\hline
\end{tabular}

The model validation was focused on the air cushion model because the air cushion gave a high impact on the pressure distribution. Based on this result, the comfortable seat would obtain by reducing the pressure change rate in the air cell.Based on the results, the pressure change rate increased because of the increasing of bus passenger weight. Due to higher input on the air cell would produce higher pressure on the air cushion model.

\section{Conclusion}

The simulation more focused on the air cushion model and the volume flow rate. Based on the results of pressure change rate, it used to determine the comfortable level with the variable parameters of air cells. The results showed that the air cell height is able to improve the comfortable level of the bus passenger's seat. Increasing in term of air cell height would gave a $45 \%$ deceased in the pressure change rate. According to Boateng [11], the higher value in reducing of the pressure change rate, the more comfortable seat provided.

\section{References}

[1] W. Shen, A. Vertiz: Redefining seat comfort, SAE Technical Paper, 970597 (1997).

[2] C.F. Tan, W. Chen, G.W.M. Rauterberg, G.W.M. Total design of active neck support system for economy class aircraft seat, Applied Mechanics and Materials. 372 (2013) 657-660.

[3] C.F. Tan. Smart system for aircraft passenger neck support. PhD Thesis, Eindhoven University of Technology (2010)

[4] T.M. Seigler. A Comparative Analysis of Air-inflated and Foam Seat Cushions for Truck Seat, Blackburg, Virginia (2002)

[5] C.R. Mehta, L.P. Gite, S.C. Pharade, J. Majumder, M.M. Pandey.Review of Anthropometric Considerations for Tractor Seat Design, Industrial Egonomics. 38 (2007) 546-554.

[6] H. Fazlollahtabar, A subjective framework for seat comfort based on a heuristic multi criteria decision making technique and anthropometry, Applied Ergonomics. 42 (2010) 16- 28.

[7] X. Wu, S. Rakheja, P.E. Boileau, Study of human seat interface pressure distribution under vertical vibration, International Journal of Industrial Ergonomics. 21, 6 (1998) 433-449.

[8] A. Kumar, N.J. Bush and K. Thakurta: Characterization of occupant comfort in automotive seats. IBEC 94, AutomotiveBody Interior and Safety Systems (1994)

[9] V.T. Bartels, Thermal comfort of aeroplane seats: influence of different seat materials and the use of laboratory test methods, Applied Ergonomics. 34 (2003) 393-399.

[10] N. Prasad, V.K.T. Ari, R. Yadav: Tractor ride vibration: A review, Terramechanics. 32, 4 (1995) 205-219.

[11] A.B. Ofori-Boeteng: A Study of the Effect of Varying Air-Inflated Seat Cushion Parameters on Seating Comfort, Master Thesis (2003) 